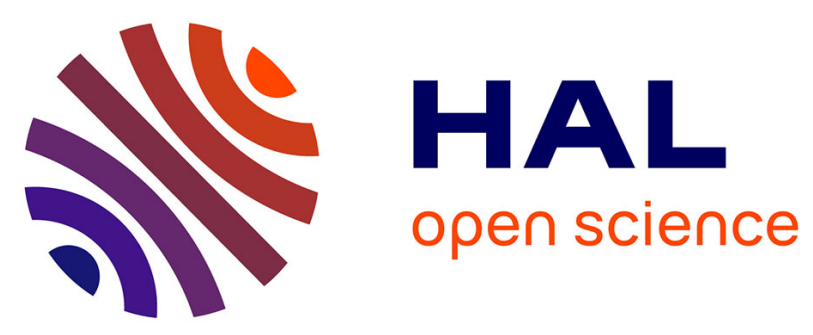

\title{
Challenges, Innovative Architectures and Control Strategies for Future Networks: The Web-of-Cells, Fractal Grids and Other Concepts
}

Georges Kariniotakis, Luciano Martini, Chris Caerts, Helfried Brunner, Nicolas Retière

\section{To cite this version:}

Georges Kariniotakis, Luciano Martini, Chris Caerts, Helfried Brunner, Nicolas Retière. Challenges, Innovative Architectures and Control Strategies for Future Networks: The Web-of-Cells, Fractal Grids and Other Concepts. CIRED 2017 - 24th International Conference on Electricity Distribution, Jun 2017, Glascow, United Kingdom. pp.1287. hal-01518368

\section{HAL Id: hal-01518368 \\ https://hal.science/hal-01518368}

Submitted on 4 May 2017

HAL is a multi-disciplinary open access archive for the deposit and dissemination of scientific research documents, whether they are published or not. The documents may come from teaching and research institutions in France or abroad, or from public or private research centers.
L'archive ouverte pluridisciplinaire HAL, est destinée au dépôt et à la diffusion de documents scientifiques de niveau recherche, publiés ou non, émanant des établissements d'enseignement et de recherche français ou étrangers, des laboratoires publics ou privés. 


\section{CHALLENGES, INNOVATIVE ARCHITECTURES AND CONTROL STRATEGIES FOR FUTURE NETWORKS: THE WEB-OF-CELLS, FRACTAL GRIDS AND OTHER CONCEPTS}

\author{
George KARINIOTAKIS \\ MINES ParisTech, PSL-Research University, PERSEE, France, \\ georges.kariniotakis@mines-paristech.fr
}

\author{
Luciano MARTINI \\ RSE, Italy \\ luciano.martini@rse-web.it
}

\author{
Chris CAERTS \\ VITO, Belgium \\ chris.caerts@vito.be
}

\author{
Helfried BRUNNER \\ AIT, Austria \\ helfried.brunner@ait.ac.at
}

\author{
Nicolas RETIERE \\ G2Elab-UGA - France \\ nicolas.retiere@g2elab.grenoble-inp.fr
}

\begin{abstract}
The large-scale deployment of distributed generation including intermittent renewable energy sources introduces several challenges to power systems operation and planning. Although power systems often evolve in a fairly incremental way to meet these challenges, the ambitious objectives for RES development in the next decades (2030-2050), together with the deployment of storage options and active demand, indicate that a more essential paradigm change shift may be required. This paper presents the future challenges and the state of the art of research works that study new concepts for the power systems of the future, with a particular focus on the Web-of-Cells concept, multi-microgrids, the fractal grid approach and autonomic power systems.
\end{abstract}

\section{INTRODUCTION}

The large-scale deployment of distributed generation including intermittent renewable energy sources (RES) introduces several challenges to power systems operation and planning [1]. Although power systems often evolve in a fairly incremental way to meet these challenges, the ambitious objectives for RES development in the next decades (2030-2050), together with the deployment of storage options and active demand, indicate that a more essential paradigm change may be required, involving:

- a centrally managed system including dispatchable generation-following load with all ancillary services to safeguard quality and security of supply,

- a move towards distributed systems with intermittent generation and bi-directional flows that increase in magnitude and complexity, with an evident trend for load-following generation to achieve similar or higher quality and security of supply.

Numerous ongoing research activities in the "smart-grid" area focus on the development of new technologies and their integration into power systems. However, in recent years a trend has emerged to consider new concepts for the architecture of power systems that analyse alternative paths to the standard incremental evolution. This paper aims to present the future challenges for power systems and the research directions on innovative concepts being developed. These include architectures like the Web-of-
Cells concept, the fractal grid, the autonomic grid, etc., along with additional concepts like the multi-microgrid approach.

\section{FUTURE POWER SYSTEM CHALLENGES}

By 2030/2050, anticipated changes in the electricity grid include at least the following:

\section{- Generation will shift from standard dispatchable} units to intermittent renewables

It is expected that by 2030 , between $52 \%$ and $89 \%$ of electricity production will result from RES [4][5]. Scenarios are even more aggressive under the 2050 scope, where the European Commission foresees $97 \%$ of electricity generation from RES. This will result in a paradigm shift from generation-following load to loadfollowing generation, and a significantly increased need for balancing reserve activations. The consequent replacement of a significant portion of large synchronous rotor-based generation by RES (typically interfaced to the grid via power electronic converters) will cause reduced power system inertia, in turn resulting in a much higher rate of change of frequency during system disturbances. In addition, reserve capacity will generally be provided by peaking power plants (to a greater extent than large CCGT), flexible loads and/or storage. Storage is expected to be a competitive alternative for peaking power plants to offer ancillary services as early as 2020 .

- Generation will largely shift from central connected transmission systems to decentralized connected distribution system generation

More injection of power into the LV and MV distribution grid will increase the risk of local voltage problems and congestions (especially given the expected increase in electricity consumption). The location of the sources of voltage issues and balancing problems that require reserve activation will partially shift from central transmission system level (HV) to distribution system level $(\mathrm{MV} / \mathrm{LV})$. A high percentage of the resources that can help to address voltage and balancing problems, i.e. resources that can provide ancillary reserves support, will move from central transmission system level (HV) to distribution system level (MV/LV). Central system operators (HV located) will no longer have a system overview to effectively dispatch reserves, requiring 
essential coordination between operators of different voltage levels and geographical areas to take into account the state of the entire distribution system. Finally, the distribution and availability of resources (production as well as storage) may vary significantly from one location to the next.

\section{- Generation will shift from a few large units to many smaller sources}

Electricity production units connected to the distribution grid will typically be much smaller than today's large central power plants. There will be a shift towards more electricity production connected to the distribution grid, since electricity generation will move from a few large plants to many smaller units. Some large central power generators will remain, but they will be increasingly RES in nature (e.g. large wind-power plants (onshore and offshore), hydro-electric power plants, marine energy parks, etc.). Incidents (such as generation outages) will occur in more locations and be more likely, but individual incidents will have a lower, more localised, impact. Local - distribution system level - incidents may have a local impact that goes unnoticed at a global system level. Since the production portfolio within the overall power system will be subject to changes throughout the day (e.g. renewable generators are weather and time dependent), the electromechanical time constant (and system response time) of the power system will consequently change depending on the weather and time of day.

- Electricity consumption will increase significantly The European GHG emission reduction targets will result in a drive for electric transport, heating and cooling, resulting in an expected increase in electricity consumption of around 43\% [6].

- Electrical storage will be a cost-effective solution for offering ancillary services

According to the recommendations for the European Energy Storage Technology Development Roadmap [7], prices of (electrical) storage are expected to drop, making distributed storage a competitive solution compared to traditional resources for reserve services. Furthermore, the energy storage roadmap maintains that distributed storage located at utility substations in distribution systems has a much higher value than central storage because it provides distribution network upgrade deferral and circuit stability control.

- Ubiquitous sensors will vastly increase the power system's observability

With the proliferation of distributed generation, and the dramatic fall in the price of sensors and solutions expected over the next few years, the inclusion of sensing and monitoring systems is starting to make compelling economic sense. These systems will be essential for providing grid operators with a holistic view of the grid and its critical components. This will result in many more measurement points at all voltage levels, such as Phasor Measurement Units (PMUs), smart metering infrastructure, etc.
- Large amounts of fast-reacting distributed resources (can) offer reserve capacity

Vast amounts of flexible loads will be available at all voltage levels, especially low voltage. The same holds for local storage. Both of these resources have very fast reaction and ramp times. Additionally, both will be connected - through Information and Communication Technology (ICT) infrastructure - to grid operators and market parties that offer flexible capabilities as a service. A high number of distributed resources with a large variety (production as well as consumption and storage resources) will be available and capable of providing Frequency Containment Reserves (possibly imposed participation through regulation). Finally, a high number of distributed resources with a large variety (production as well as consumption and storage resources) will be able to provide Balance Restoration Reserves.

- Developments in ICT will support the pathway towards more decentralized managed power systems

The developments of ICT and their massive introduction into the power system in recent decades have completely changed monitoring, operation and planning methods. Without the possibility of data generation and, most importantly, data and information exchange, even the liberalisation of the energy sector would not have been possible. The last mile of the power system is about to be covered by ICT, which also supports the massive integration of small-scale generation, prosumers, storage, e-mobility and demand response. Additional support will be provided thanks to the progress and development of the Internet of Things (IoT) and big data. IoT may lead to a complete rethinking of LV grid operation use cases. The number of IoT-ready appliances (sensors, meters, inverters, home management systems, etc.) in low voltage grids is rising sharply. These appliances can be used for additional services like forecasting load, generation and flexibility requests.

\section{STATE OF THE ART ON INNOVATIVE ARCHITECTURES}

To address the above challenges, a number of research projects go beyond incremental research and investigate innovative concepts and architectures in view of the power system evolution by 2030/2050. One of these innovative architectures is the Web-of-Cells (WoC) concept developed in the frame of the EU project ELECTRA. This project, which focuses on real-time voltage and frequency control of the electrical grid, developed the WoC concept to anticipate the active grid that will prevail with the penetration of distributed energy resources (wind, solar, storage, etc.). It assumes a novel organization of the power system into cells, where power balancing and other functionalities are performed within specific areas as illustrated in Figure 1. An alternative concept is being developed by the Fractal Grid project (ANR) in France and some initiatives in the US. The 
fractal grid approach aims to exploit auto-similarities in power system structures to understand the complexity and emergent properties of power grids; optimize spatial organization of urban patterns and networks; and increase the flexibility and resilience of power grids. It also proposes grey- and green-feed approaches to develop new grids or extend existing ones based on fractal concepts.

Alternative concepts include the multi-microgrid approach, which permits a hierarchical organization of the distribution network into multiple microgrids each of which optimizes operations locally, and the autonomic power system. These concepts are described in more detail below.

\section{The Web-of-Cells concept}

Due to the challenges of integrating distributed energy sources, we can reasonably expect that a decentralized control concept solving local problems locally will best address the fundamental changes in the future power system [4], [5]. The ultimate scope of the European ELECTRA Integrated Research Programme (IRP) [8][9] is related to real-time reserve activation that takes place after the market parties end their balancing activities; it addresses real-time deviations compared to the scheduled balance resulting from forecast errors (in load or generation) or incidents (see Figure 1).

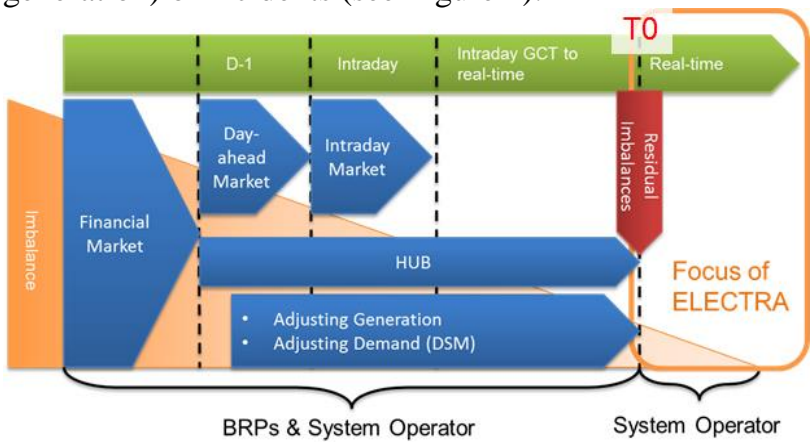

Figure 1: Timeline of Balancing Procedure in the web of cells concept.

The growing volume of intermittent generation from Renewable Energy Resources (RES) at all voltage levels, the increasing electrical load due to the electrification of heating and transport, and the active control of flexible loads raise a number of issues related to reverse power flows, local congestions and voltage problems that challenge the current centralistic reserves activation practice. The first challenge involves detection, as local load and generation deviations in Low Voltage (LV) and Medium Voltage (MV) power distribution areas may balance each other out and remain unnoticed by central system operators who base their decisions on a global variable like frequency. The second challenge concerns activation. More and more reserve activations will be carried out using devices located at the LV and MV networks, and it is crucial to ensure that such activations do not cause additional problems in these local grids. Maintaining the current centralistic detection and activation paradigm would require significant detailed local information to be collected, aggregated and communicated from all LV and MV networks to the High Voltage (HV) transmission system operator, who could then detect local problems and determine action to ensure grid-secure, optimal reserve activation using LV and MV connected (flexible) resources.

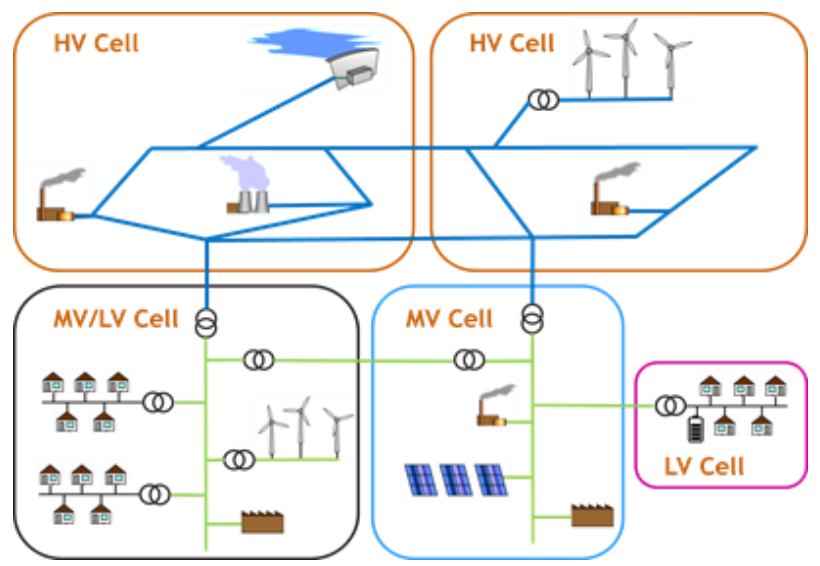

Figure 2: Schematic example of the proposed "Web-of-Cells" architecture

For these reasons, ELECTRA IRP proposes a decentralized control scheme, called Web-of-Cells. The core focus of this approach is the handling of local intercell tie-line power flow deviations - comparable to the well-known Area Control Error, but at cell level - rather than system frequency, where the responsibility for detecting and correcting such real-time deviations is delegated to local operators (see Figure 2). This results in less (computational) complexity and less communication. To limit the number of reserve activations in such a decentralized paradigm, a peer-to-peer inter-cell coordination mechanism is proposed to achieve a localized imbalance netting result. Obviously, local voltage problems will increase, and will need to be handled by a local cell operator due to their local nature. This opens opportunities for more active voltage control, where local optimal set-points are repeatedly determined based on up-to-date local information and forecasts.

\section{The Fractal Grid project approach}

The research project Fractal Grid [11] aims at proposing a new architecture paradigm for smart grids based on fractality. Indeed, self-similarities of territories and power systems have already been observed [16]. A basic hypothesis is that future power systems will become organizationally fractal, consisting of the recursive assemblage of multiple smart buildings, micro-grids, smart cities, distribution grids, national and international networks [17]. Because Fractal Grids should yield a more flexible, controllable, resilient and interoperable electrical system that enables efficient and safe operation, the 
project methodology "goes back to basics" by developing an innovative multi-scale methodology to address the increased complexity of future power systems.

The major methodological challenges addressed by Fractal Grid are multiscale modeling and design. Multiscale means that the project will consider aspects ranging from weather systems and market organization down to electrical network topologies, with a particular focus on the latter. Key points of the project methodology are shown in Figure 3.

Multiscale approaches can also be used to analyze power transmission as distribution systems. The Fractal Grid project firstly focuses on distribution systems covering inter- or intra-urban territories. Some links will be made with the upper level system in order to study the vertical interactions inside the global electrical network.

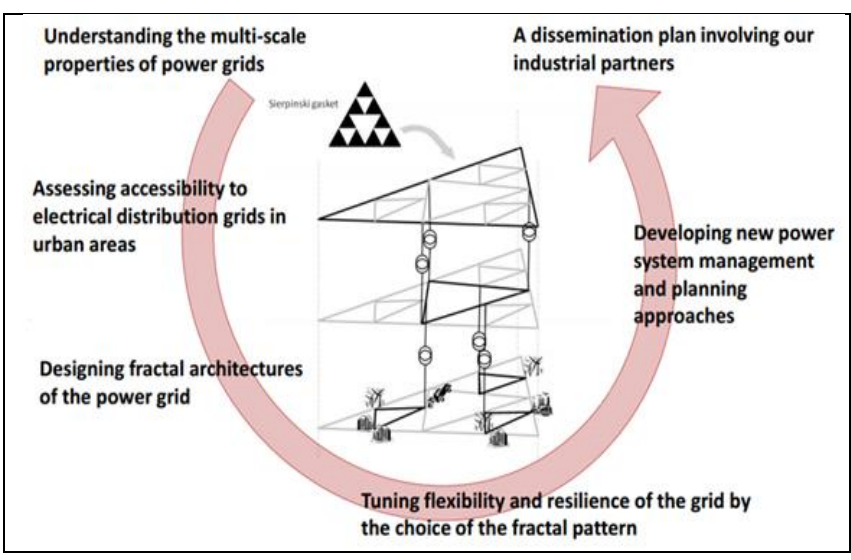

Figure 3: Research directions of the Fractal Grid approach

Multiple research results have shown that settled space is often structured according to fractal logic and recent investigations have compared the coherency between the spatial organization of urban built-up spaces and street networks [17]. A similar approach is suitable for power systems. A given built-up area corresponds to an optimal topology of the power grid. This results from the spatial distribution and power of the loads, the technical constraints, such as the maximal voltage variations, and the global cost. This latter cost is the sum of three components: the investment cost, the power losses cost and the non-supplied energy cost if the network is not reliable enough. Of course, the optimal solution is highly dependent on the spatial arrangement of the built-up area. Multi-scale analysis aims to characterize this dependency at different scales of observation and determine how it influences the optimization of the power grid topology. For this purpose, the fractal dimensions of built-up areas is computed. These dimensions characterize how the built-up areas fill the space.

Moreover, fractal analysis identifies scales in which spatial organization changes. To identify ruptures or shifts in the scaling behavior, a special method has been developed for urban pattern analysis [17]. A similar analysis will be performed for electrical distribution networks. This analysis will improve understanding of the spatial organization of the distribution network on inter-urban and intra-urban scales, and identify hypertrophies and deficiencies in existing networks. It is also intended to study the link between consumers' distribution in urban areas and network morphology. This could also be relevant when considering decentralized energy production.

\section{The Autonomic Power System}

The Autonomic Power System project, developed by a number of universities in the UK [18], aims to move beyond current smart grid applications and approaches. The concept is based on biological autonomic systems that set high-level goals but delegate decision-making on how to achieve them to lower level intelligence. No centralized control is apparent, and behavior emerges from low-level interactions. This allows highly complex systems to achieve real-time and just-in-time optimization of operations.

The autonomic power system is a completely integrated and distributed control philosophy that self-manages and optimizes all network operational decisions in real time. To deliver this, fundamental research is being conducted to determine the achievable level of distributed control (or the balance between distributed, centralized, and hierarchical controls) and its impact on investment decisions, resilience, risk, customer participation and control in a trans-national interconnected electricity network.

\section{Multi-microgrids}

The concept of a microgrid has been extensively developed in Europe, initially in the frame of the FP5 Microgrids project and the follow-up FP6 project MoreMicrogrids [19]. Concepts and research work developed in these projects are consolidated in [20]. In addition, field tests at real systems have demonstrated microgrid functionalities i.e. experiment islanding for the first time in Europe for several hours using only batteries and renewable generation. Following completion of these research projects, the priority was to bring the concepts developed towards technological maturity through demonstration projects. Currently, several large-scale demonstration projects implement and test microgrid concepts in real systems, like the FP7 project GRID4EU and its French demonstrator Nice Grid. These projects have tested islanding operations based on batteries and renewable generation, the impact of high penetration of renewables into the $\mathrm{LV}$ grid, concepts on centralised or decentralised control, and different business models etc. The concept of a multi-microgrid, which was studied in [19], [20], has not however been demonstrated. The microgrid is a cell that aims to use local resources in an optimal way. Given its small size, microgrid operators are most likely to operate multiple microgrids. Implementing a multi-microgrid concept implies technical and 
commercial integration of multi-microgrids, that is, interfacing several microgrids with the upstream Distribution Management Systems, and operating decentralised markets for energy and ancillary services. Multi-microgrids require a higher level structure, formed at MV level and consisting of LV microgrids and distributed generation units connected to several adjacent MV feeders. The development of this concept poses further challenging problems due to the increased network dimension and operation complexity, since it involves operating a high number of LV micro-sources and loads together through an MV grid. In the future, the industrial deployment of microgrids will most probably result in management schemes that imply multiple microgrids.

\section{DISCUSSION}

The innovation potential of the future power system is identified in the following specific areas:

- A flexible and adaptive set of active grid components capable of efficiently delivering the quality of supply specified by grid rules and/or grid codes, irrespective of size or position (central or regional).

- A technology-independent electricity grid system capable of offering the required services of the connected users with implied cost optimization embedded in the system architecture.

- An electricity grid system that makes no distinction (or bias) between the connected users but determines distinct roles for efficiently managing the interconnected system.

- An electricity grid system that fully supports the integrated grid for global optimization but remains fully responsive to local specificities for flexibility, responsiveness and technology neutrality.

Although most current efforts are dedicated to demonstration projects that aim to bring smart grid technologies closer to the industry and end-users, a number of research projects focus on more fundamental research and address the evolution of the power system beyond 2030/2050. Some aspects of the developed techniques make them eminently scalable and could be taken from simulation into experimental testing. One of the perspectives of this work is to monitor the results of these projects and compare their differences and similarities. In parallel, it is necessary to follow the evolution of research work on the synergies between different energy networks like electricity, gas and district heating networks.

\section{ACKNOWLEDGEMENTS}

The research leading to these results received funding from the European Union $7^{\text {th }}$ Framework Programme (FP7/2007-2013) under grant agreement $n^{\circ}$ 609687. It was also supported by the project Fractal Grid funded in part by the French National Research Agency (ANR) under grant $\mathrm{N}^{\circ}$ ANR-15-CE05-0007-02.

\section{REFERENCES}

[1] European Commission, "EU Reference Scenario 2016. Energy, transport and GHG emissions trends to 2050", 2016.

[2] Wuppertal Institute for Climate, Environment and Energy, "Technical analysis and comparison of underlying scenarios for the forthcoming European Commission White Paper on a 2030 climate and energy policy framework", 2014.

[3] TU Wien Energy Economics Group, "2030 RES targets for Europe: a brief pre-assessment of feasibility and impact", 2014.

[4] H. Farhangi, "The path of the smart grid", IEEE Power and Energy Magazine, vol. 8, no. 1, pp. 18-28, Jan./Feb. 2010 .

[5] T. Strasser et al., "A Review of Architectures and Concepts for Intelligence in Future Electric Energy Systems", in IEEE Trans. on Industrial Electronics, vol. 62, no. 4, pp. 2424-2438, April 2015.

[6] European Renewable Energy Council, "RE-thinking 2050, a 100\% Renewable Energy Vision for the European Union", 2010.

[7] EASE/EERA, "Joint EASE/EERA recommendations for a European Energy Storage Technology Development Roadmap towards 2030", 2013.

[8] Further details are available at www.electrairp.eu.

[9] L. Martini et al., "ELECTRA IRP approach to voltage and frequency control for future power systems with high DER penetration", 23rd Int. Conf. on Electricity Distr., CIRED 2015, 15-18 June 2015, Lyon (FR).

[10] EASE/EERA, “Joint EASE/EERA recommendations for a European Energy Storage Technology Development Roadmap towards 2030”, 2013.

[11] www.fractal-grid.eu

[12] Navigant Research, "Utility spending on Asset management and Grid Monitoring Technology will reach nearly \$50 Billion through 2030", 2014.

[13] J. Kreusel, "GRID4EU optimises the medium voltage grid”, Renewable Energy Focus, vol. 17, no. 5, pp. 194197, Sep./Oct. 2016.

[14] N. Fonseca et al., "evolvDSO grid management tools to support TSO-DSO cooperation", CIRED Workshop 2016, 14-15 June 2016, Helsinki (FI).

[15] M.H. Syed et al., "Laboratory Infrastructure Driven Key Performance Indicator Development using the Smart Grid Architecture Model", 24th Int. Conf. on Electricity Distr., CIRED 2017, 12-15 June 2017, Glasgow (UK).

[16] N. Retière, "Exploring the Scale-Invariant Structure of Smart Grids.", IEEE Systems Journal, In press, Available on line Oct. 2014.

[17] I. Thomas, P. Frankhauser, "Fractal dimensions of the built-up footprint: buildings versus roads. Fractal evidence from Antwerp (Belgium)," Environ. Plan. B Plan. Des., vol. 40, no. 2, pp. 310-329, 2013.

[18] http://autonomicpowersystem.org.uk/

[19] http://www.microgrids.eu

[20] N. Hatziargyriou editor, "Microgrids: Architectures and Control”, John Wiley and Sons Ltd, Chichester, U.K. 